\title{
Research on: Improving Students Group Discussion Skill in Mathematics Class
}

\author{
Negeri Negese Wayesa \\ Department of Mathematics, College of Natural and Computational Science, BuleHora University, Bule Hora, Ethiopia
}

Email address:

negerirome@gmail.com

\section{To cite this article:}

Negeri Negese Wayesa. Research on: Improving Students Group Discussion Skill in Mathematics Class. Science Journal of Education. Vol. 8, No. 4, 2020, pp. 94-99. doi: 10.11648/j.sjedu.20200804.11

Received: June 12, 2020; Accepted: July 24, 2020; Published: August 10, 2020

\begin{abstract}
These researches aimed to identifywhy students achieve low results in mathematics subject as well as providing possible solutions to this problem. With reference to the researchers' experiences as teachers at schools and later at universities and after seeing the academic results of students on mathematics courses, they found that there are weaknesses in the students' academic achievement. In fact, academic achievement is considered very necessary for students to transfer from one studying level to another, so the researchers found that it is crucial to investigate improving student's skill in mathematics. When learners' are followed mathematics course group discussion/learning is essential. Group work is a method of social work which develops the ability of establishing constructive relationship in individuals through group activities. Group experiences are the essential needs of human being. Group work helps the individual in removing weakness and strengthening internal power to perform his/her job satisfactorily. The social group worker must have the theoretical knowledge of social group work, its principles, its skills, its models; its assumption so that he/she may be able to perform his/her jobs most satisfactorily. The mathematics skills hardship faced by students during mathematics solving equations and problem-solving. so as to understand the issues faced by them, The study was carried out using a qualitative method involving a group work of students developing their cognitive abilities in learning further intricate the trouble faced by the students in their mathematics solving equations and problem-solving.
\end{abstract}

Keywords: Improving, Group Discussion, Skill in Mathematics

\section{Introduction}

\subsection{Background of the Study}

Education is structural and systematic tool, which is used to acquire knowledge through interaction of pupils with themselves and with their physical and social environment. As it is known addressing quality education is the main agenda for many developing countries like Ethiopia. Due to this fact Ethiopia ministry of education prepared the higher diploma program for university teachers. The program includes action re-search need to be performed by the trainee to solve some problems on various topics focused/associated on quality of education [1].

In other words through this interaction the students develop their own personality and intellectual thinking ability. This can take place in the class room teaching learning process with an appropriate teaching mechanism.
Therefore in teaching learning process different teaching methods and strategy must be applied and designed. From those Group Discussion is the main one.

We know the group discussion is a best method that allows students to share ideas and discuss together in team work. As a result, this method is the best one to improve active learning method and as well as to bring quality of education.

A problem solver is someone who questions, finds, investigates and explores solutions to problems; demonstrates the ability to stick with a problem to find a solution; understands that there may be different ways to arrive at an answer; and applies math successfully to everyday situations. We encourage our child to be a good problem solver by including him in routine activities that involve math.

Based on the assessment an in conjunction with the client, during the contracting phase of social work practice you attempt to define clearly the issues and goals for work and develop plans likely to resolve the identified issues and 
achieve the final goals. Reflecting on the particular pedagogical benefits we would like to see our students reap through group work can help you establish guidelines for the creation of group contracts. For example, [2, 3] advocate for group work where groups assign roles that rotate regularly among members in order to provide each student the opportunity to practice important teamwork skills.

Social group work is a method of social work which develops the ability of establishing constructive relationship in individuals through group activities [4]. Group experiences are the essential needs of human being.

\subsection{Statement of the Problem}

In BuleHora university Department of civil Engineering first year second Semester Particularly Group I in Mathematics class; the majority of students in inquiry knowledge by involving in the activity or group discussion are unsatisfactory. They have low interest on group formation, low participation in group discussion, low interaction within each other and poor in their readiness for new learning because have experience by the traditional presentation (Lecture) or teaching methodology. By observing these problems of students the researcher want to help them:

i. By increase students awareness about the importance of learning through group discussion (interpersonal interaction) which in turn (promotes) students learning and participation.

ii. Given advice to change their attitude toward group discussion and to have an interesting idea, sharing idea among them.

iii. Developed initiation and motivation to learn and will be get better knowledge through group activities.

\subsection{Objectives of the Study}

\subsubsection{General Objectives}

Group discussion method is one of the proper teaching learning systems to bring creative and problem solving citizen.

\subsubsection{Specific Objectives}

The present study will be carried out in order to find out the strengths and limitations of the new interventions introduce to the improvements of students skill in mathematics. the research study formulated the following objective:

i. Point out the importance of group activity.

ii. To encourage students in learning activities and working together for their common and individual target or goal.

iii. To make subject mathematics as an interesting subject by delivering the lesson in active, attractive and collaborative manner.

iv. To identify and involve the root causes of the problems that influences the participation of students in group activities.

v. To describe how class room participation will improve.

\subsection{Research Question}

The following research questions will design to meet the objective of the study:

i. What are the areas of the problem on participation of group activity?

ii. What is the role of the teacher and student in class room?

iii. Is students actively participate and follow teacher?

iv. Is it Students team work develop skill in Mathematics?

\subsection{Significance of the Study}

This part shows the benefits and beneficiaries of the result of the research being conducted. It states the importance and contribution that will be identified the problem of the participation of group activities in BuleHora University Department of Civil Engineering Group I, the finding of the study help fully provide possible ways overcoming the participation in teaching learning process. In a discussion group the objectives are usually broader, deeper and often less precise than in a typical exercise class; as such there is less pressure to produce detailed correct work. There is more room for personal opinion (although not too much in mathematics), and debate can range over a wider area. The students have more control over the proceedings, more personal input and opportunities for direct feedback; they can also follow their own interests much more easily.

\section{Review Literature}

\subsection{Cooperative Learning}

Cooperative learning involves small group of learners who work together as a team to solve a problem, complete a task or accomplish a common goal $[5,6]$. In traditional education systems, the students are assigned a passive role. They listen to the teacher, absorb what the teacher says and produce what the teacher has said at a later time. Teacher is the presenter of the information and he/she is in the center of the classroom there is a clear boundary between the teacher and the students and the interaction between them is highly limited [7]. In cooperative learning the roles of teachers and students have changed [8]. Students are at the center and the teacher becomes a coordinate or facilitator of learning resources. The students are encouraged to be successful active learners. Cooperative Learning also helps students develop self-steam and enhances their ability to learn. Low achieving students can imitate the study skills and work habits of more proficient students.

\section{A. Advantage of cooperative Learning}

The advantage is cooperative Learning enhances opportunities for Mathematics learning because students learn from each other's ideas [9]. In a similar way cooperative Learning supports critical thinking and higher level processing skills as students challenge each other while reaching a group decision [10]. Students improve their communication and social skills and often gain self-steam as they work toward a common goal.

B. Disadvantages of cooperative Learning

Disadvantages of cooperative Learning is classrooms become noisy and teachers have less control as the students begin 
working independently. Cooperative Learning requires extra time and may lead to discontinuity in the curriculum [11]. Time is needed to teach students procedures and skills of working effectively in cooperative groups.

\subsection{Cooperative Learning in Mathematics}

Working within a group at school helps students develop efficient team skills. It improves their communication abilities needed in cooperative learning settings [12],[13]. Cooperative Learning method has recently attracted scholarly attention than other teaching methods because its sociology, psychological, educational, and pedagogical benefits. Many research findings underlined the positive cognitive and affective results' Mathematics achievement, develop friendships between students and enhance self-steam [14].

\subsection{Discussion Groups in Mathematics}

Discussion Groups are not often used in Mathematics teaching; they are more common in arts or social science based disciplines [15]. In Mathematics such a group, normally small, comes together to discuss an extended problem or application, mini-project, or perhaps a particularly extended and important proof. The object is to deeper understanding by debate and interaction and to sharpen analytical and logical skills. Communication and Mathematical Learning The national research council has identified five strands for mathematical proficiency (16):

i. Conceptual understanding-comprehension Mathematical concepts, operations and relations.

ii. Procedural fluency- skill in carrying out procedures flexibility, accurately, efficiently and appropriately.

iii. Strategic competence- ability to formulate represent and solve mathematical problems.

iv. Adaptive reasoning- capacity for logical thought, reflection, explanation and justification.

v. Productive disposition- habitual inclination to see mathematics as sensible, useful and worthwhile, coupled with a belief in diligence and one's own efficacy.

Reflective thought involves carefully analyzing what is being said, making judgments, and understanding how that new information fits with prior knowledge. On the other hand if new information does not fit, reflective thoughts requires that existing ideas be adjusted with the new ones [17]. Typically new learning and deeper understanding result from this reflective thinking process. By sharing, explaining and justifying ideas, students develop skills in reasoning and engage in sense-making.

So, the researcher conclude their ideas; Group discussion techniques are used to encourage students to develop their own thinking and support each other's ideas and By explaining the material to the others higher achieving students often develop a deeper understanding of the task or master a sharper skill. Since explanation is one of the best means for establishing connections, and students in cooperative setting often give explanation to each other, the likelihood of constructing rich networks of knowledge under this conditions increase.

\section{Methodology}

\subsection{Design of the Study}

This Action research conducted at BuleHora University Department of Civil Engineering Group I, the main reason why the researcher preferred to conduct the present Action research. the researcher give solution for the students skill in Mathematics by doing team work and the collected data will be organized and put in suitable way (tabulate form) that can be well interpreted the data tabulated form of data organized by using descriptive and different historical tools like present and tables.

\subsection{Instrument of Data Collection}

The Instrument of the researcher will collect different evidences in different ways by using:

i. To collect the necessary information employed the questionnaire and systematic observation conduct using check list type of data collection techniques to reach the solution.

ii. The instrument of such collection data open and closed ended questionnaire and interview delivered to sample.

iii. To collect information from students by using questionnaire and interview question.

\subsection{Sampling Techniques and Sample Size}

It is difficult to involve all students in the study. Because lack of time; for this research the sample size of 15 students selected from the total of Female: 10, Male: 30, Total: 40 students of first year Civil Engineering Group I.

\subsection{Data Analysis}

The collected data from Questionnaires, Interview and observation analyzed using both qualitative and quantitative table used to analysis acquired data.

\subsection{Actions to Be Implemented}

To improve class participation of low achiever students, the following strategies will be implemented:

i. Teaching some of the basics of mathematics in tutorial classes.

ii. Counseling the importance of class participation.

iii. Providing tutorial class to those students before regular classes.

iv. Use of active learning methods students prepare before classes.

\section{Result and Discussion}

The results of the study were presented in line with the research questions and hypotheses. 


\subsection{Research Question One: What Is the Advantage of Group Discussion in Mathematics Class}

The group work benefits the conscious understanding of the basic principles of social group work. because this knowledge provides him/her a frame work to work with the group Encouragement of each member to participate according to the stage of their capacity and enabling them to become more capable.

The importance of group activity, respondents $100 \%$ puts the following points:

i. Thinking clearly about group problems, findings, causes and working for solutions.

ii. Sharing the leadership jobs among the group members and show sensitivity to the feelings of all.

iii. The group worker is the central work. The worker is the object of identification and drives.

iv. Group activity changes the level of individual aspirations and desires.

v. The capacity to solve problems increased through group discussion.

vi. Exchanging ideas among the members freely and clearly, using language understood by everyone and with no fears of starting arguments or hurting feelings.

So, group discussion is useful for students (or any social group). When the researcher gives conclusion, group work gives: develop thinking, communication skill, having capacity to solve problem, to increase love each other and etc.

\subsection{Research Question Two: What Are the Disadvantages of Group Activity}

The disadvantage of group discussion is:

i. Time consuming.

ii. Needs large class size.

iii. Groups are more difficult to manage than one individual; interviewer must keep track of what is going on in the group.

iv. The environment can have an impact on the responses.

v. Open-ended structured interview format must be used.

vi. He teacher may feel like they are losing control of the class

\subsection{Research Question Three: Which Applies the Teacher Teaching Methodology}

In the class the teacher uses different teaching methodology. Such like group discussion, demonstration and lecture method. When we describe by the table:

Table 1. Types of teaching methodology.

\begin{tabular}{llll}
\hline No & Income group & frequency & Percent \\
\hline 1 & Group discussion & 7 & $47 \%$ \\
2 & Demonstration & 5 & $33 \%$ \\
3 & Lecture & 3 & $20 \%$ \\
\hline
\end{tabular}

As students mentioned on table above the teacher used teaching methodology more apply group discussion (47\%) and uses sometimes lecture $(20 \%)$.

\subsection{Research Question Four: What Is Factors Affecting Using Group Activity}

Students have different personal behaviors which are unique and having paramount effect on their class activity. Some of these behaviors make them to participate more while some others negatively affect their participation. From this point of view analysis of some important student's personal behavior was made and the results are disturbing the class, high achiever is not opened, sometimes chance of playing for students.

\subsection{Research Question Five: What Kind of Skills Do You Imagine Students Practice with in Their Group}

Skill means the capacity to perform activities.

Trecker defines skill means the purposeful use of insights and understanding based upon a body of knowledge and principles. Skill is the capacity to apply knowledge and understanding to a given situation. The respondents mentioned below the kind of skill practice with their group:

i. Skill of Working with the Individual outside the Group of Meetings.

ii. Skill of Communication of Feelings.

iii. Skill of Using the Reality of the Present.

iv. Skill in Evaluation.

v. Skill of Explaining

\subsection{Research Question Six: What Are the Effective Whole Class Discussions}

As the respondents give answer the researcher used tables and puts their answer by percent.

Table 2. Effective Whole Class Discussions.

\begin{tabular}{llll}
\hline No & Income group & frequency & Percent \\
\hline 1 & Excellent & 4 & $26.7 \%$ \\
2 & Very good & 8 & $53.3 \%$ \\
3 & good & 3 & $20 \%$ \\
\hline
\end{tabular}

From the above table four students out of fifteen students or $26.7 \%$ the effective whole class discussion are excellent, $53.3 \%$ students are very good while $20 \%$ are good.

So, the effective whole class discussions are very good.

Students develop an understanding of math when they talk about math, listen to others, and observe a variety of representations $[18,19]$ Whole class discussions must lead to the development of a more sophisticated understanding of mathematics and build on student thinking by addressing different strategies and errors that students make [20]. Classroom discussion time must be used effectively and efficiently. Whole class discussion is to help students develop a conceptual understanding of mathematics and more efficient strategies through mathematical reasoning and sense-making [21]. Students in a whole class discussion that supports mathematical learning are active participants. The discussion builds on student responses. So, in the mathematics class the students develop their critical thinking and to make self confidence as we see on the figure the Civil Engineering 
department works together and helping each other. Characteristics of effective class discussions that support learning, from respondents:

a) Discussion is open ended with opportunities.

b) Students engage in sense-making.

c) The purpose of the discussion is to understand a mathematical problem.

d) Teacher acts as a facilitator and Students explore how to solve problems and understand why the approach works.

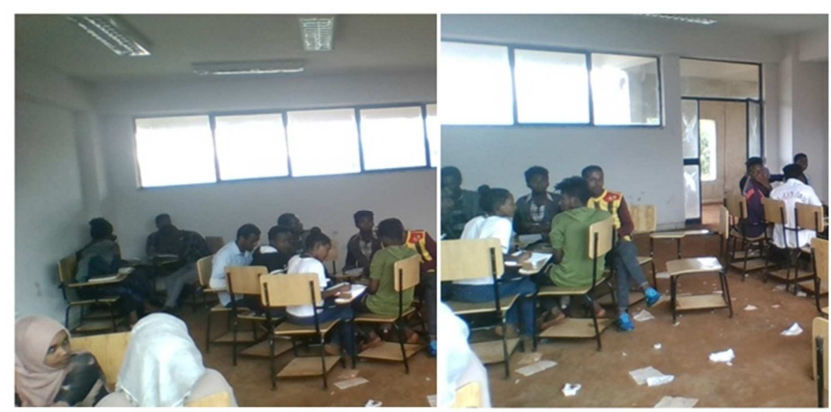

Figure 1. Group work in class room Conclusion and Recommendation.

\section{Conclusion and Recommendation}

\subsection{Conclusion}

Group discussions help to summarize the ideas and information that a group of informants may come to hold as a group, rather than the information held by the individual members. The general idea is that each participant can act to stimulate ideas in the other people present, and that by a process of discussion the collective view becomes greater than the sum of the individual parts. Group discussions form a part of such techniques as Brainstorming and Focus groups, and these will be discussed in turn. Group discussions are very common in the user requirement stage of product development. Discussion groups are used in mathematics teaching; to deepen understanding by debate and interaction and to sharpen analytically and logical skills. Students develop skills of constructing logically based arguments and precise reasoning skills, since ideas raised must be tested promptly and arguments mathematically justified.

\subsection{Recommendation}

Based on the findings of our action research the following recommendations are made to improve student's mathematics skill.

i. Students haven't backgrounds of mathematic and they know mathematics is difficulty out of all subject. So aware students mathematics is not difficult and the backbone of all subject and our future life.

ii. Guidance and counseling their family and students

iii. Letting students prepare before classes

iv. Updating their confidence when they are participated of their group.

\section{Acknowledgements}

I would like to forward my thanks to science publication group and editorial assistance (Taylor Doris) who advice on my paper to Research Publication and The author is grateful to his wife, Mrs. Rome Kenasa for her contributions to the publication of this paper.

\section{References}

[1] Wondemetegegn, S., Ahmed, A., \& Zelalem, T. (2016). The Role of the 'Post Graduate Diploma in Secondary School Teaching'Program in Improving the Quality of Teaching in Eastern Ethiopian Secondary Schools. Multidisciplinary Journal of School Education, 9 (1).

[2] Chapman, O., \& Wood, L. (2004). Teachers' beliefs influencing the implementing of a project-based high school mathematics curriculum.

[3] Skemp, R. (1971). The Psychology of Learning Mathematics. Harmondsworth: Penguin Books.

[4] Northen, H., \& Kurland, R. (2001). Social work with groups. Columbia University Press.

[5] Rio, R. R. (2002). Teaching and learning Mathematics: From secondary school to university, MEC.

[6] Kurnia, E. (2002). The effect of using cooperative learning by using jigsaw activities and the traditional technique on the reading comprehension achievement of SMU YPPI-I students, Surabaya (Doctoral dissertation, Widya Mandala Catholic University Surabaya).

[7] Gibson, S., \& Dembo, M. H. (1984). Teacher efficacy: A construct validation. Journal of educational psychology, 76 (4), 569 .

[8] Singha, K. G. Goswami, M. Bharali, R. K. (2012). Study of various problems faced by the students and teachers in learning \& teaching mathematics and their suggestive measures, International Journal of Advanced Research in Management and Social Sciences.

[9] Hänze, M., \& Berger, R. (2007). Cooperative learning, motivational effects, and student characteristics: An experimental study comparing cooperative learning and direct instruction in 12th grade physics classes. Learning and instruction, 17 (1), 29-41.

[10] Souviney, R. (1983). Mathematics achievement, language and cognitive development: Classroom practices in Papua, New Guinea. Educational studies in mathematics.

[11] Robinson, A. (1990). Cooperation or exploitation? The argument against cooperative learning for talented students. Journal for the Education of the Gifted, 14 (1), 9-27.

[12] Jbeili, I. M. A. (2003). The effects of metacognitive scaffolding and cooperative learning on mathematics performance and mathematical reasoning among (Doctoral dissertation, Universiti Sains Malaysia).

[13] National Council of Teachers of Mathematics (2008, March). The role of technology in the teaching and learning of mathematics. 
[14] Spencer, P. L. \&Russel, D. (1960). Reading in arithmetic.

[15] Pia, K. F. (2015). Barriers in Teaching Learning Process of Mathematics at Secondary Level: A Quest for Quality Improvement, American Journal of Educational Research.

[16] Felder, R. M. and Brent, R. (2001). Effective strategies for cooperative learning.

[17] Morss, K. and Murray, R. (2005) Teaching at University: A Guide for Postgraduates and Researchers, Sage Publications, London.
[18] Ray, B. (2010). Academic Achievement and Demographic Traits of Homeschooled Students: A Nationwide Study, Academic Leadership, 8 (1), 1-44

[19] Reasoner, R. (2012). The True Meaning of Self-Esteem. Indian Journal of Applied Research, 1 (12), 83-84

[20] Rothery, A. (Ed.). (1980). Children reading mathematics. Worcester: College of Higher Education.

[21] Von Waltershausen, W. S. (1965). Gauss zum Gedächtniss. Sändig Reprint Verlag H. R. Wohlwend (1856, reprinted 1965). 